\title{
Blood transfusion practices in a tertiary care hospital in Nepal
}

\author{
Amar Narayan Shrestha ${ }^{1}$, Barun Babu Aryal ${ }^{2}$, Ayusha Poudel ${ }^{2}$, Prakrit Chhetri², \\ Shraddha Poudel ${ }^{2}$, Anurag Adhikari ${ }^{2}$, Shreya Shrestha ${ }^{2}$ \\ ${ }^{\prime}$ Department of Pathology, Shree Birendra Hospital, Chhauni, Kathmandu, Nepal \\ ${ }^{2}$ Shree Birendra Hospital, Chhauni, Kathmandu, Nepal
}

\section{Keywords:}

Blood transfusion;

Cross match;

Transfusion index;

Utilization;

\section{ABSTRACT}

Background: Blood transfusion is an integral part of patient management. Good transfusion practice guided by standard protocols is considered ideal for optimal use of resources and manpower. Cross-match requests disproportionate to the actual requirement causes overestimation of blood usage and potential wastage. This study aims to determine the crossmatch, transfusion, and utilization rates for blood using transfusion index, and cross-match to transfusion ratio in the various departments of the hospital for the evaluation of transfusion practices.

Materials and Methods: A retrospective study was conducted using the records from the hospital blood bank for 12 months to obtain transfusion and cross-match records from various clinical units. Transfusion requests, units cross-matched, and completed transfusions were used to calculate the cross-match to transfusion ratio, and transfusion index for each department.

Results: A total of 5156 units of blood were cross-matched for 3437 transfusion requests, out of which 3752 were transfused, giving a mean cross-match to transfusion ratio of 1.37 . The non-usage of blood was $27.2 \%$ and the transfusion index stood at 1.09 . The cross-match to transfusion ratio for the individual clinical units ranged from 1.75 (Surgery) to 1.14 (Medicine).

Conclusions: The cross-match to transfusion ratio and transfusion index were within recommended ranges, showing good utilization and low blood wastage. The establishment of a blood ordering protocol via a multidisciplinary approach should be considered to further optimize blood transfusion practices.

\section{Correspondence:}

Dr. Amar Narayan Shrestha, $M D$

Department of Pathology, Shree Birendra Hospital,

Chhauni, Kathmandu, Nepal.

ORCID ID: 0000-0003-4300-4223

Email: shresthaaamar@gmail.com

Reveived : August $2^{\text {nd }} 2020 ;$ Accepted : September $25^{\text {th }} 2020$

Citation : Shrestha AN, Aryal BB, Poudel A, Chhetri P, Poudel S, Adhikari A, Shrestha S. Blood transfusion practices in a tertiary care hospital in Nepal. J Pathol Nep 2020:10:1728-32.. DOI: 10.3126/jpn.v10i2.30424

Copyright: This is an open-access article distributed under the terms of the Creative Commons Attribution 4.0 International License, which permits unrestricted use, distribution, and reproduction in any medium, provided the original author and source are credited.

\section{INTRODUCTION}

Blood is a valuable resource for patient management in hospitals. Worldwide, more than 110 million blood donations are done every year, and those in the southeast Asian region comprise about $15 \%$ of total donations. ${ }^{1}$ Whole blood accounts for $89 \%$ of all blood transfusions while apheresis accounts for the remaining $11 \%$. The indications for blood transfusions vary from place to place. Blood transfusions for supportive care in cardiovascular and transplant surgery, massive trauma, and therapy for solid and hematological malignancies are the most common uses in developed countries, while transfusions to treat pregnancy-related complications and severe childhood 
anemia are more common in developing countries. ${ }^{2,3}$

Blood transfusion carries the potential to cause adverse effects such as immune and non-immune mediated transfusion reactions, as well as exposes the recipient to various transfusion transmissible diseases. Overestimation of blood usage, especially in resource-constrained settings, burdens the transfusion services in terms of unnecessary usage of reagent, time, and manpower. Over-ordering of blood leads to financial loss for the patient, an increase in cost during hospital-stay, and an increase in overall demand for blood. Thus, the ordering of blood and blood components must be fully justified to avoid misuse or overuse. The cross-match to transfusion $(\mathrm{C} / \mathrm{T})$ ratio is used as a measure of the efficiency of blood ordering practice. A ratio of 2.5 and below is generally considered indicative of significant blood usage. ${ }^{4} \mathrm{~A} \mathrm{C} / \mathrm{T}$ ratio of more than 2.5 means that less than $40 \%$ of cross-matched blood is transfused, which indicates excessive cross-matching of blood for a specific procedure..$^{5-7}$ Transfusion index (TI) value of 0.5 or more is generally considered indicative of significant blood utilization. $^{4}$

In developing countries like Nepal, the provision of blood and blood products on time is a challenging task due to various factors such as lack of voluntary donors, lack of a robust healthcare network, and inadequate storage and transport facilities. Excessive ordering of blood products and low usage probability further exacerbates the problem. Hence, periodic review and standardisation of transfusion practices are helpful for optimization of blood and blood components utilization, and as a result, improving their availability.

This study was undertaken to evaluate the blood transfusion practices in a tertiary care hospital in Nepal by determining the pattern of transfusion requests, blood utilization, $\mathrm{C} / \mathrm{T}$ ratio, and TI. We aim to provide a snapshot of where the TI of the hospital lies compared to other hospitals and to formulate general recommendations that will hopefully prove useful in future efforts to optimize blood utilization

\section{MATERIALS AND METHODS}

This retrospective study was conducted at the Shree Birendra Hospital, Chhauni, Kathmandu, Nepal over one year from $14^{\text {th }}$ April 2017 to $11^{\text {th }}$ April 2018. Permission to carry out the study was obtained from the institutional review committee. The hospital blood bank database was used to obtain crossmatch request and transfusion request forms from clinical units including departments of Internal Medicine, Surgery, Pediatrics, Gynecology/Obstetrics, Emergency, Intensive Care Unit, Dialysis, and Oncology during the study period. Transfusion requests, units cross-matched, and completed transfusions were determined for each department and used to calculate the $\mathrm{C} / \mathrm{T}$ ratio (Total units crossed matched/ Total units transfused), non-usage probability (Total units not transfused/ Total units cross-matched), and transfusion index (TI) (number of units transfused/number of patients cross-matched). ${ }^{8-9}$

As per the hospital policy, all blood products issued out, if not utilized, are returned to the blood bank for proper storage, and whenever possible, crossmatched for another transfusion request. All units issued out and not returned to the blood bank were considered utilized (transfused).

\section{RESULTS}

A total of 5156 units were cross-matched based on 3437 requests for transfusion during the study period of 12 months. The Surgery department had the highest number of transfusion requests $(n=1064 ; 30.9 \%)$, followed by the Department of Medicine $(n=639 ; 18.5 \%)$. The highest number of blood units were cross-matched for the Surgery department ( $\mathrm{n}=1596 ; 46.4 \%)$.

Out of 5156 cross-matched units, 3752 units (72.7\%) were transfused. This gave an average $\mathrm{C} / \mathrm{T}$ ratio of 1.37 for the entire hospital. Department of Surgery had the highest $\mathrm{C} / \mathrm{T}$ ratio of 1.75 followed by the Emergency department (1.72). Department of Medicine had the lowest $\mathrm{C} / \mathrm{T}$ ratio of 1.14, indicating the most efficient usage of blood within

Table 1: Number of transfusion requests, cross-matching, transfusion, C/T ratio, and TI according to department

\begin{tabular}{|c|c|c|c|c|c|c|}
\hline Departments & $\begin{array}{l}\text { No. of Transfusion } \\
\text { requests }\end{array}$ & $\begin{array}{l}\text { No. of units } \\
\text { cross-matched }\end{array}$ & $\begin{array}{l}\text { No. of units } \\
\text { transfused } \\
\text { n }(\%)\end{array}$ & $\begin{array}{l}\text { No. of units not } \\
\text { transfused } n \\
(\%)\end{array}$ & $\mathrm{C} / \mathrm{T}$ ratio & TI \\
\hline Medicine & 640 & 958 & $839(87.5)$ & $119(12.4)$ & 1.14 & 1.31 \\
\hline Surgery & 1064 & 1596 & $907(56.8)$ & $689(43.2)$ & 1.75 & 0.85 \\
\hline Gynae/Obs & 415 & 623 & $416(66.7)$ & $207(33.2)$ & 1.49 & 1.00 \\
\hline Pediatrics & 74 & 111 & $96(86.4)$ & $15(13.5)$ & 1.15 & 1.30 \\
\hline Oncology & 284 & 426 & $320(75.1)$ & $106(24.9)$ & 1.33 & 1.13 \\
\hline Dialysis & 430 & 645 & $538(83.4)$ & 107 (16.6) & 1.19 & 1.25 \\
\hline ICU & 410 & 616 & $531(86.2)$ & $85(13.8)$ & 1.16 & 1.30 \\
\hline Emergency & 120 & 181 & $105(58.0)$ & $76(41.9)$ & 1.72 & 0.88 \\
\hline Total & 3437 & 5156 & 3752 & 1404 & & \\
\hline
\end{tabular}


the hospital. The mean transfusion index for the hospital was 1.09. Similarly, the highest TI was seen in the Medicine department (1.31) followed by Pediatrics (1.297), and the lowest was seen in the Surgery department (0.85). (Table 1)

The non-usage value for the hospital stood at $27.2 \%$ as 1404 of the 5156 cross-matched units were not transfused. Nonusage was the highest for the department of Surgery (43.2\%) and the lowest for the department of Medicine (12.4\%).

\section{DISCUSSION}

The main finding of this study is that the mean $\mathrm{C} / \mathrm{T}$ ratio of all the departments is 1.37 . The mean non-usage value is $27.2 \%$ and the mean TI is 1.09 for the hospital. The surgery department had the highest $\mathrm{C} / \mathrm{T}$ ratio of 1.75 and the highest non-usage value of $43.2 \%$, while the department of medicine had the lowest $\mathrm{C} / \mathrm{T}$ ratio of 1.14 and a non-usage of 12.4 percent.

Overall, the study found the mean $\mathrm{C} / \mathrm{T}$ ratio in our hospital to be lower than those reported in other tertiary centers in different regions of Nepal and neighboring South Asia countries like India and Pakistan. A pilot study on blood ordering and transfusion practice in routine operation theatres in a tertiary care hospital in Eastern Nepal found a $\mathrm{C} / \mathrm{T}$ ratio of $6.7 .{ }^{10} \mathrm{~A}$ study on blood transfusion practices in a tertiary care center in northern India found a $\mathrm{C} / \mathrm{T}$ ratio of 1.6. ${ }^{11}$ A study conducted in Egypt in 2011 showed a similar overall CT ratio of 3.9 for a wide range of surgical procedures. ${ }^{4}$ The mean $\mathrm{C} / \mathrm{T}$ ratio is also lower than that reported from other studies from Benin (2.2), Nigeria (2.9), and Saudi Arabia (2.96). ${ }^{12-14}$

A lower $\mathrm{C} / \mathrm{T}$ ratio indicates better utilization of blood. While the blood that is issued and unused can be returned to the blood bank and potentially reused, non-usage can still lead to increased strain on resources and increases the chance of wastage. The observed differences in utilization may be due to different transfusion policies at different hospitals. In our hospital, blood typing ( $\mathrm{ABO}$ and $\mathrm{Rh}$ ) is done before the storage of blood in the blood bank, and cross-matching is only done when transfusion is needed. Moreover, indications of blood transfusions vary depending on the clinical status of patients and their treating clinicians. ${ }^{15}$ Possible causes of high $\mathrm{C} / \mathrm{T}$ ratio include lack of clear blood ordering policies in hospitals, lack of clinical audits, and communication between clinicians and blood bank health care workers.

Our finding of a higher $\mathrm{C} / \mathrm{T}$ ratio for the Surgery department when compared to the overall $\mathrm{C} / \mathrm{T}$ ratio of the hospital is expected, and consistent with other studies. ${ }^{11-14}$ This could be explained by the need for a precautionary arrangement of blood in various surgical procedures, for use in case of significant blood loss. ${ }^{16}$ A large proportion of these procedures end up not requiring blood transfusion, which contributes to the high $\mathrm{C} / \mathrm{T}$ ratio. Additionally, preoperative blood ordering tends to be guided more by habit than clinical needs for the specific case. ${ }^{17}$ The C/T ratio in the Surgery department in this study, though higher than that for other departments, was still within the generally accepted range of less than 2.5, and also lower than $\mathrm{C} / \mathrm{T}$ ratios reported for surgical units in other studies. ${ }^{18}$ This could be due to differences in department protocols for blood arrangement for procedures in different hospitals.

The TI pattern is similar to those found in other studies done in various parts of the world. A study done by Soleimanha $\mathrm{M}$ et al found the TI to be $0.6 \cdot{ }^{19}$ Other studies have also shown similar results with high $\mathrm{C} / \mathrm{T}$ ratios but $\mathrm{TI}$ within the generally accepted range. ${ }^{4}$

The current study is limited by its retrospective design and use of secondary data, which introduces errors like typing errors and missing records. We were unable to determine various other indices of blood utilization due to a lack of detailed records. Additionally, there is also a high variation of the primary index ( $\mathrm{C} / \mathrm{T}$ ratio) between hospitals, likely due to the difference in indications for blood ordering based on the type of hospital. A direct comparison with other hospitals is thus difficult.

Instead of cross-match for transfusion practices, the policy of using a type and screen protocol has been proven to be effective without compromising patient safety. ${ }^{20,21}$ Other measures with proven improvement in $\mathrm{C} / \mathrm{T}$ ratio and $\mathrm{TI}$ are maximum surgical blood ordering schedule (MSBOS) and type, screen, save, and abbreviated cross-match (TSSAC). The MSBOS uses retrospective analysis of actual blood usage for various elective surgical procedures to specify the number of blood units to be cross-matched for these procedures. ${ }^{22}$ In TSSAC, the patient's $\mathrm{ABO}$ and $\mathrm{Rh}$ groups are identified and screening of the patient's blood is done for irregular antibodies. Full cross-matching is done only if irregular antibodies are found. Otherwise, a quick spin cross-match is done only if the blood is eventually needed for transfusion. ${ }^{23}$

Studies have found MSBOS to be a viable option for reducing unnecessary cross-matching and achieving significant cost savings for the blood bank. ${ }^{24-26}$ However, Murphy et al found that "use of an MSBOS does not appear to influence clinical usage of blood for transfusion". ${ }^{27}$ Palmer et al found patient-specific blood ordering system, which includes patient and surgeon variables in transfusion prediction to be more accurate than the MSBOS, which uses only the surgical procedure to estimate blood requirement. ${ }^{28}$ Nuttall et al formulated a surgical blood ordering equation which incorporated patient factors in the ordering of blood for surgical patients. ${ }^{29}$ 
Incorporation of some of these systems into transfusion practice in hospitals could potentially improve the $\mathrm{C} / \mathrm{T}$ ratio. ${ }^{30-35}$ For elective surgeries, the arrangement of blood only after the completion of pre-anesthetic checkup and when final surgery is planned can be considered. Regular auditing and periodic feedbacks are vital to improving blood utilization practices in the hospital. A more meticulous approach to record-keeping in the hospital would also help with regular audits and progress tracking.

The financial cost is a serious consideration for patients in developing countries. Due to the limited adoption of health insurance, and limited social security, the average Nepali usually has to bear the full cost of healthcare, which can be quite high. Establishing and adhering to a blood ordering protocol has been proven to reduce the financial burden to the patient, especially for elective surgical procedures. ${ }^{4,35}$ Thus, formulating a blood ordering and transfusion protocol tailored to the hospital's needs, with input from all departments concerned, can reduce the non-usage of crossmatched blood units and thus optimize blood transfusion practices.

\section{CONCLUSIONS}

We found the $\mathrm{C} / \mathrm{T}$ ratio, non-usage probability, and transfusion index to be within generally recommended ranges, showing good utilization and low wastage of blood. Overestimation of the use of blood products is not a major concern at this hospital based on our findings. However, the establishment of an efficient and safe blood ordering and transfusion protocol via a multidisciplinary approach should be considered to further reduce the non-utilization of crossmatched blood units and thus optimize blood transfusion practices.

\section{Conflict of interest: None}

\section{REFERENCES}

1. World Health Organization. Global status report on blood safety and availability 2016. Geneva: World Health Organization. 2017. Website

2. Wells AW, Mounter PJ, Chapman CE, Stainsby D, Wallis JP. Where does blood go? Prospective observational study of red cell transfusion in north England. BMJ 2002;325:803. Crossref

3. Mafirakureva N, Khoza S, Hassall O, et al. Profiles of blood and blood component transfusion recipients in Zimbabwe. Blood Transfus 2015;13(4):600-9. Crossref

4. Hasan O, Khan EK, Ali M, Sheikh S, Fatima A, Rashid HU. "It's a precious gift, not to waste": is routine cross matching necessary in orthopedics surgery? Retrospective study of 699 patients in 9 different procedures. BMC health services research. 2018;18(1):804. Crossref

5. Alghamdi S, Gonzalez B, Howard L et al. Reducing blood utilization by implementation of a type-and-screen transfusion policy a singleinstitution experience. Am J Clin Pathol 2014 Jun;141(6):892-5. Crossref
6. Thabah R, Sailo LT, Bardoloi J et al. 'Maximum Surgical Blood Order Schedule'in a newly set-up tertiary care hospital. Anaesthesia, Pain \& Intensive Care. 2019;17:28-32. Website

7. Chow EY. The impact of the type and screen test policy on hospital transfusion practice. Hong Kong Med J. 1999;5(3):275-9. Website

8. Boral L, Henry J. The type and screen: a safe alternative and supplement in selected surgical procedures. Transfusion. 1977;17(2):163-8. $\underline{\text { Crossref }}$

9. Khoshrang H, Madani AH, Roshan ZA, Ramezanzadeh MS. Survey on blood ordering and utilisation patterns in elective urological surgery. Blood Transfus. 2013;11(1):123-7. Crossref

10. Chaudhary RK, Singh RK, Pokharel K, Bhattarai B. Blood ordering and transfusion practice in routine operation theatres of BPKIHS: a pilot study. Health Renaissance. 2012;10(2):137-8. Crossref

11. Kumari S. Blood transfusion practices in a tertiary care center in Northern India. Journal of laboratory physicians. 2017 Apr;9(2):71. Crossref

12. Ebose EM, Osalumese IC. Blood shortage situation: An audit of red blood cells order and pattern of utilization. African Journal of Biotechnology. 2009;8(21): 5922-5. Crossref

13. Musa AU, Ndakotsu MA, Hassan AA, Kilishi A, Kwaifa IK. Pattern of blood transfusion request and utilization at a Nigerian University Teaching Hospital. Sahel Medical Journal. 2014;17(1):19. Crossref

14. Bashawri LA. Pattern of blood procurement, ordering and utilization in a University Hospital in Eastern Saudi Arabia. Saudi Med J. 2002;23(5):555-61. Website

15. Fasola FA, Shokubi WA. Audit of the red cell units supply of a busy hospital blood bank in Nigeria. Nigerian Journal of Clinical Practice. 2009;12(2): 165-8. Website

16. Rund RL, Bird AR, MFMJ. Blood usage in elective surgery: a 3-month audit at Groote Schuur Hospital, Cape Town. S Afr Med J. 1992;81(88):415-8. Website

17. Friedman BA. An analysis of surgical blood use in United States hospitals with application to the maximum surgical blood order schedule. Transfusion. 1979;19(3):268-78. Crossref

18. Karki OB. Blood Requisition and utilization practice in surgical patients in a teaching hospital, Western Nepal. Kathmandu Univ Med J 2016;53(1):27-30. Website

19. Soleimanha M, Haghighi M, Mirbolook A et al. A survey on transfusion status in orthopedic surgery at a trauma center. Arch Bone Jt Surg. 2016;4(1):70-4. Website

20. Alavi-Moghaddam M, Bardeh M, Alimohammadi H, Emami $\mathrm{H}$, Hosseini-Zijoud SM. Blood transfusion practice before and after implementation of type and screen protocol in emergency department of a university affiliated hospital in Iran. Emergency medicine international. vol. 2014, Article ID 316463, 4 pages, 2014 Crossref

21. Alghamdi S, Gonzalez B, Howard L et al. Reducing blood utilization by implementation of a type-andscreen transfusion policy a single-institution experience. American Journal of Clinical Pathology. 2014;141(6):892-5. Crossref

22. Voak D, Napier JA, Boulton FE et al. Guidelines for implementation of a maximum surgical blood order schedule. Clinical \& Laboratory Haematology. 1990;12(3):321-7. Website 
23. Wong I, Cheng G. Type and screen of blood units at a teaching hospital. Hong Kong Med J. 1995;1:27-30. Website

24. Lowery TA, Clark JA. Successful implementation of Maximum Surgical Blood Order Schedule. J Med Assoc Ga. 1989;78(3):155-8. Website

25. Hardy NM, Bolen FH, Shatney CH. Maximum surgical blood order schedule reduces hospital costs. Am Surg. 1987;53(4):223-5. Website

26. Iwasaki T, Nishiyama T, Otsuka M, Ohara Y, Kobayashi $\mathrm{O}$, Seto K. Evaluation of preoperative blood preparation and blood consumption for implementation of type and screen and maximum surgical blood order schedule. Masui. The Japanese journal of anesthesiology. 1995;44(6):880-4. Website

27. Murphy WG, Phillips P, Gray A et al. Blood use for surgical patients: a study of Scottish hospital transfusion practices. J R Coll Surg Edinb. 1995;40(1):10-3. Website

28. Palmer T, Wahr JA, O'Reilly M, Greenfield ML. Reducing unnecessary cross-matching: a patient-specific blood ordering system is more accurate in predicting who will receive a blood transfusion than the maximum blood ordering system. Anesthesia \& Analgesia. 2003;96(2):369-75. Crossref

29. Nuttall GA, Horlocker TT, Santrach PJ, Oliver Jr WC, Dekutoski $\mathrm{MB}$, Bryant S. Use of the surgical blood order equation in spinal instrumentation and fusion surgery. Spine. 2000;25(5):602-5. Crossref
30. Challand CP, Mahadevan D, Clarke A, Keenan J. Maximum surgical blood ordering schedule for revision hip and knee arthroplasty. J Bone Joint Surg Br. 2011;93:527-32. Website

31. Subramanian A, Sagar S, Kumar S, Agrawal D, Albert V, Misra MC. Maximum surgical blood ordering schedule in a tertiary trauma center in northern India: A proposal. Journal of emergencies, trauma, and shock. 2012;5(4):321. Crossref

32. Ashok K, Nitin N, Mayank V, et al. Evaluation of blood utilization in elective surgery-requirement, ordering and transfusion practices. International Journal of Health Sciences and Research. 2014;4(6):186-99. Website

33. Kaur P, Basu S, Kaur G, Kaur R. An analysis of the pattern of blood requisition and utilization in a tertiary care center. Natl J Integr Res Med. 2014;4:186-99. $\underline{\text { Crossref }}$

34. Davoudi-kiakalayeh A, Faranoush M, Haghbin A, Behboudi F. Reviewing the blood ordering schedule in a tertiary trauma center. Iranian Journal of Blood and Cancer. 2013;6(1):27-31. Website

35. Waqas M, Shamim MS, Ujjan B, Bakhshi SK. Prospective validation of a blood ordering protocol for elective spine arthrodesis and its impact on cost reduction. Surgical $\begin{array}{llll}\text { neurology international. 2014;5(Suppl 7):S362-4. } & \end{array}$ Website 